\title{
Do blind persons have better audiometric hearing threshold values than sighted persons? A pair-matching analysis.
}

\author{
Ahmed, A. ${ }^{1}$, *Tsiga-Ahmed, F. $^{2}$
}

\begin{abstract}
Objective: This study aimed to report difference in audiometric hearing threshold values between blind and sighted persons.
\end{abstract}

Methods: This was a comparative cross-sectional study of blind and normally sighted students hearing thresholds. Two groups were formed experimental and control groups respectively, matched for age only. Audiometric threshold hearing values were obtained using an Audiometer in accordance with the modified Hughson-Westlake technique at frequencies of 0.5 to $4 \mathrm{kHz}$. The Pure Tone Average is the average value at these frequencies for the better ear.

Results: Each group had 23 participants, mean threshold values for blind group was $17.45 \mathrm{~dB}(95 \% \mathrm{CI}$ : 16.59 - 18.30dB); while for the sighted group is $17.59 \mathrm{~dB}$ (95\%CI: $15.90-19.28 \mathrm{~dB})$. Overall, tests did not reveal a statistical significance even though normal sighted students had higher threshold values.

Conclusion: The study did not reveal a difference between audiometric threshold values between sighted and blind persons.

Key words: Blind, sighted, audiometric values, difference.

\author{
*Correspondence Author \\ Tsiga-Ahmed, F.I. \\ E-mail-fateetsiga@live.com; drahmedzizo@yahoo.com
}

${ }^{1}$ Department of Otolaryngology, Faculty of Clinical Sciences, College of Health Sciences, Bayero University/Aminu Kano Teaching Hospital, Kano, Nigeria

${ }^{2}$ Department of Community Medicine, Faculty of Clinical Sciences, College of Health Sciences, Bayero University/Aminu Kano Teaching Hospital, Kano, Nigeria

\footnotetext{
Research Journal of Health Sciences subscribed to terms and conditions of Open Access publication. Articles are distributed under the terms of Creative Commons Licence (CC BY-NC-ND 4.0). (http://creativecommons.org/licences/by-nc-nd/4.0)

http://dx.doi.org/10.4314/rejhs.v7i2.4
} 


\title{
Les personnes aveugles ont-elles de meilleures valeurs de seuil d'audition audiométrique que les personnes voyantes? Une analyse par appariement des paires.
}

\author{
Ahmed, A. ${ }^{1}$, *Tsiga-Ahmed, F. $^{2}$
}

\section{Resume}

Objectif: Cette étude visait à rendre compte de la différence entre les valeurs du seuil d'audition audiométrique entre les personnes aveugles et voyantes.

Méthodes: Il s'agissait d'une étude transversale comparative d'étudiants malentendants et malvoyants. Deux groupes expérimentaux et témoins ont été formés, appariés uniquement pour l'âge. Les valeurs d'audition au seuil audiométrique ont été obtenues à l'aide d'un audiomètre conformément à la technique de Hughson-Westlake modifiée, à des fréquences de 0,5 à $4 \mathrm{kHz}$. La tonalité pure moyenne est la valeur moyenne à ces fréquences pour la meilleure oreille.

Résultats: Chaque groupe comptait 23 participants, les valeurs seuils moyennes pour le groupe aveugle étant de 17,45 dB (IC 95\%: 16,59 - 18,30 dB); tandis que pour le groupe des voyants, $17,59 \mathrm{~dB}$ (IC 95\%: $15,90-19,28 \mathrm{~dB}$ ). Dans l'ensemble, les tests n'ont pas révélé de signification statistique, même si les valeurs seuils étaient plus élevées chez les élèves malvoyants.

Conclusion: L'étude n'a pas révélé de différence entre les valeurs de seuil audiométrique entre les personnes malvoyantes et les personnes aveugles.

Mots clés: Aveugle, voyant, valeurs audiométriques, différence.

\author{
*Auteur principal \\ Tsiga-Ahmed, F.I. \\ E-mail-fateetsiga@live.com; drahmedzizo@yahoo.com
}

${ }^{1}$ Department of Otolaryngology, Faculty of Clinical Sciences, College of Health Sciences, Bayero University/Aminu Kano Teaching Hospital, Kano, Nigeria

${ }^{2}$ Department of Community Medicine, Faculty of Clinical Sciences, College of Health Sciences, Bayero University/Aminu Kano Teaching Hospital, Kano, Nigeria 


\section{INTRODUCTION}

The most important special senses in the activities of the blind are the senses of touch and hearing, therefore, it is reasonable to assume that the blind possess a particular special sensitivity with reference to touch and hearing (1). Anecdotally, it is also believed that blind persons may be superior to the sighted in tasks where touch and hearing are the most important performance indicators (2). The physiologic process which allows this adaptive mechanism to occur rests in sensory cells of the nervous system. The process that allows neurons (nerve cells) in the brain to compensate for injury and disease and to adjust their activities in response to new situations or to changes in their environment is termed Central nervous system neuroplasticity. Many studies have attempted to explain Cross modelling sensory reorganization or neuroplasticity of the central nervous system in relation to this superiority of blind persons (3-6).

Hearing acuity is particularly important in the blind for locating sounds and use of alerting devices (give warning in response to danger signal) in the office or home such as alarm clocks, fire alarms, baby monitors, crossing the street, and many other functional real life benefits. Studies have suggested that the interaural level difference (ILDs) for sounds are most useful for echolocation (i.e. detection or localization of sound reflections from nearby objects and this tend to use sounds of high frequencies (7-9). How blind persons develop and maintain an internal notion of the auditory space in the absence of calibration by visual information is still a matter of much debate. Some researchers have posited that normally sighted people are able to use echolocation to perceive objects, and can develop abilities comparable to, but typically somewhat poorer than, those of blind people (10).

It would seem that sound reception is a crucial aspect of this assumed 'superiority' of the blind over the sighted. Under more specific experimental conditions, auditory-spatial abilities were demonstrated to be even more superior among individual blind persons e.g., with monaural localization in the horizontal plane, with binaural localization of eccentric sound locations or with auditory distance discrimination (10).

The question would now be whether the audiometric threshold scores for the blind are better than for the sighted at normal speech frequencies? There is paucity of statistical modelling of the threshold scores in sub-Saharan
Africa. A study carried out in 2013,(3) revealed that hearing thresholds did not differ, neither between the total group of blind subjects nor with sighted controls. With this information, there is need to gather more evidence regarding peculiarities of hearing threshold value among the blind and sighted in our environment to fill gaps in knowledge of this phenomenon.

Therefore this study aimed to report any difference in audiometric threshold values between the blind and sighted participants.

\section{MATERIALS AND METHODS}

This was a comparative cross-sectional study of blind students at a special school for the blind in Kaduna, Northwestern-Nigeria.

$\mathbf{H}_{0}$ - is that there is no difference, or no change in the audiometric/hearing threshold values between the blind and normally-sighted students. $\mathbf{H}_{1}$ - is the research hypothesis, is that there is a difference, or change in the audiometric/hearing threshold values between the blind and normallysighted students.

Sample size was calculated using the guide suggested by Ronán Conroy,(11) using expected mean value and standard deviation for the comparison group, as well as estimating the smallest difference between the test and control group that would be considered scientific or clinically important (estimated standard deviation $(\mathrm{SD})=3.5)$. A difference in mean hearing thresholds of $3 \mathrm{~dB}$ between blinded subjects and normal sighted subjects would be regarded as clinically significant, since the average ear can detect at least a $3 \mathrm{~dB}$ change in sound.

Consequently, the number of participants needed in each group to detect a difference of this size would be; $3 / 3.5=0.86$ (minimum difference to be detected). Using the table (11) for sample size corresponding to 0.86 $($ approximately 0.90$)=26$.

Therefore, to have a $90 \%$ chance of detecting this difference, 26 subjects would be required in each group (total of 52 subjects). However, allowing for dropout and not sure if sample will be normally distributed, the total was multiplied by a factor $(11)$ of $1.16(52 \times 1.16)=$ 60.32. An estimated total of 60 subjects was needed for the study. Stratified random sampling technique was used to select all subjects. The strata for the blind school comprised of five special schools for the deaf/blind and blind, names of students of this school were then 
selected from the schools database/register and a computer used to generate the required number and names randomly.

A total of 30 blind subjects (group 1) were recruited alongside another thirty normal sighted secondary school students (group 2) within the same vicinity matched for age to serve as controls. A normal school was selected from a list of schools for normal hearing children by simple random sampling, then selecting 30 subjects using a computer generated random list of the students.

Normal hearing impairment was considered to be $25 \mathrm{~dB}$ or less based on WHO criteria (12) Therefore, this was used as an inclusion criterion to select both cases and controls with age range of 10 to 30years (to eliminate age related hearing changes, and this range adequately covers students in secondary education in our environment). Subjects with history of hearing impairment, ear disease, and trauma to the head were excluded prior to sampling.

To assess hearing acuity using audiometric testing, a calibrated Kamplex diagnostic audiometer AD 17 with TDH 39 headphones was used and a biological check was performed each morning prior to testing. This biologic check involves testing at least 2 persons with known stable hearing thresholds to make sure there are no baseline threshold changes in the Audiometer. Pure-tone audiometry (PTA) was conducted in accordance with the modified Hughson-Westlake ascending technique. Air conduction thresholds were established separately for the left and right ear of each subject respectively, as recommended by World Health Organization (WHO), which requires the establishment of sensitivity at frequencies of 0.5 , 1,2 , and $4 \mathrm{kHz}$ to estimate average hearing thresholds. However, the Pure Tone Average (PTAv) is the average value at these frequencies based on hearing scores of the subjects' better ear. The hearing testing took place in a room at the school adjudged to have an ambient background noise level $\leq 40 \mathrm{~dB}$ (A) SPL using sound level meter SL-4010, Lutron Electronics. Each measurement was repeated three (3) times from different angles prior to testing to increase reliability.

Hearing testing and examination was performed by 2 trained Audiometricians and 3 Otolaryngologist (otoscopy using a Heine Mini $3000 \AA$ Otoscope) while 2 Ophthalmologist examined the eye (using a Snellen's chart, ophthalmoscope and Loupe) to confirm visual loss/impairments. Four subjects declined to further participate at the stage of audiometric testing while 10 subjects did not meet the audiometric inclusion criteria. We did not perform bone conduction and/or immitance/tympanometry testing during the survey.

Permission and Ethical clearance was obtained from the State Ministry of Education, Ethics committee with further permission to carry out the testing from the schools' principal and parent teachers association (PTA), while consent was obtained from the students. This study was conducted according to the ethical principles of the World Medical Assembly revised declaration of Helsinki (2013).

\section{Data Analysis}

IBM SPSS (for Windows, version 21) software was used to analyze generated data. Descriptive statistics using Excel was used to examine demographic data and hearing ability at different frequencies. A non-parametric independent test (Mann Whitney U test), was used to explore the difference between blind sighted students audiometric hearing thresholds and that of the control group.

\section{RESULTS}

\section{Test of Normality and main effects}

Results from the Shapiro-Wilk $(p=0$ $.001 ;$ statistic $=0.710 ; \mathrm{df}=23 ;$ Lilliefors Significance Correction) test for the blind hearing threshold values were significant, indicating that the threshold values were not normally distributed, whereas hearing threshold values for the control (normal students) group was normally distributed $(P>0.05)$. Therefore, we chose the Mann-Whitney $U$ test for the data analysis because one of the groups (blind group values) were not normally distributed.

The first group had twenty three blind subjects (Six females and seventeen males) with a mean of age 15.7 years ( $\pm 2.87 \mathrm{SD})$; CI $95 \%$ : $14.46-16.93$. While the second group had twenty three normal subjects to serve as controls (12 males and 11 females) with mean age 16.9years ( \pm 4.60 SD); CI 95\%: 14.92 - 18.90 .

Overall, the group with the highest mean rank was the control (normal sighted) group which had the highest audiometric threshold values (table 2). The results of the tests did not reveal a statistical significance even though normal sighted students had higher threshold values $(U=247.500, p=.711)$ table 3 . 


\section{DISCUSSION}

These results indicated audiometric hearing values among normally sighted group as being higher than among the blind group even though this was not statistically significant. We attempted to investigate the neuroplasticity of blind subjects in our environment using pure tone audiometry to assess perception of puretones sound with that of normally sighted subjects (Table 1). It would seem as if this adjudged advantage of blind persons as alluded to by some researchers $(3,13)$, may not be entirely plausible in the auditory spatial domain.

We tested basic discrimination abilities relevant to sound perception using pure tone audiometry to clarify how this aspect of hearing fares among sighted and blind listeners. There is evidence that many blind people develop impressive hearing skills that help them navigate in their environment $(6,10,14)$, which also buttresses the saying that blind persons may be superior to the sighted in tasks where touch and hearing are the performance indicators.

Conversely, according to some psychophysical data on sound localization $(15,16)$, in the horizontal plane only small, if any, differences was recorded between blind and sighted individuals which also agrees well with our observation. Furthermore, experiments with animal models have also reported minimal differences between blind and sighted, thereby concurring with our finding as well (17). Similarly, studies that assessed locating sound sources in the horizontal plane under binaural hearing conditions failed to find any significant differences in general accuracy between blind and sighted human subjects (18-19).

In this study, the normally sighted subjects had higher audiometric mean rank values, than the blind group (table 2), even though blind subjects had better or more acute hearing than their sighted counterparts, statistically, better hearing could not be established among them. The difference in mean ranks is illustrated in table 3 , where the p-value revealed a lack of statistical significance. Similar reports from experimental paradigms, requiring detection of changes in sound location, blind participants usually showed some advantage when sounds were located in the peripheral auditory space, but were as accurate as sighted controls or even worse in central space $(3,20)$.

The task of listening to a sound source in a non-acoustic booth as in this study, is quite simple enough, but may also be a limitation accounting for the lack of significant difference in our blind and sighted subjects' audiometric values. What may have been better is the use of sound-proof listening room to assess sound perception and audiomotor feedback with an ambient sound pressure level below $25 \mathrm{~dB}(\mathrm{~A})$. Using this strategy, there is evidence that, at least in the horizontal dimension, long-term visual deprivation results in a normal representation of the auditory space, as alluded to by other researchers in the "model of visual calibration of the auditory space in the blind" (3). The researchers posit that the model of calibration of the auditory space by audiomotor feedback in the absence of vision predicts that blind persons (regardless of whether blindness is congenital or late) must rely more intensely on the analysis of auditory motion cues than sighted persons who are able to use visual calibration. This then means the central mechanisms analyzing sound motion may be substantially better trained in blind, than in sighted persons (3). Furthermore, our sample size may have been too small to produce a significant outcome and as such not generalizable.

As a preliminary study, our design is novel because it draws on a pair matching statistical approach which may guide future research into identifying fundamental auditory abilities in which blind people excel. Similarly, we aim to assess in the future interaural level difference, monaural/binaural localization in the horizontal/vertical plane, or sound localization in eccentric sound locations among blind and sighted individuals.

\section{CONCLUSION}

This study shows that there was no difference between audiometric threshold values between sighted and blind students. It also adds to the literature on auditory abilities of sensory impaired persons and, in particular, to research comparing normal sighted and visually challenged persons but further research is required. Such research may have practical implications for the development of programmes for disabled persons, targeting specific auditory abilities.

Acknowledgment: We would like to appreciate all the students of the five special education schools in Kaduna town, for their cooperation and support, their teachers and most of all their parents, we all had fun. We are also grateful to Professor Samaila E, Dr. Emmanuel Abah, Dr. Oladigbolu KK for their resilience and support during data acquisition and the entire exercise. 
The authors declare no assistance or financial support from any source.

Conflict of interest: The authors declare no conflict of interest.

\section{REFERENCES}

1. Bates Mary. Super Powers for the Blind and Deaf: The brain rewires itself to boost the remaining senses. 2012 [May 20, 2019]; Available from: https://www.scientificamerican.com/article/supe rpowers-for-the-blind-and-deaf/?redirect=1.

2. Gandhi PH, Gokhale PA, Mehta HB, Shah CJ. A comparative study of simple auditory reaction time in blind (congenitally) and sighted subjects. Indian journal of psychological medicine. 2013;35(3):273-7.

3. Lewald J. Exceptional ability of blind humans to hear sound motion: implications for the emergence of auditory space. Neuropsychologia. 2013;51(1):181-6.

4. Hötting K, Röder B. Auditory and auditory-tactile processing in congenitally blind humans. Hear Res 2009;258(1-2):165-74.

5. Voss P, Lepore F, Gougoux F, Zatorre RJ. Relevance of spectral cues for auditory spatial processing in the occipital cortex of the blind. Frontiers in Psychology. 2011;2:48.

6. Collignon O, Voss P, Lassonde M, Lepore F. Cross-modal plasticity for the spatial processing of sounds in visually deprived subjects. Exp Brain Res. 2009;192:e343-58.

7. Rowan D, Papadopoulos T, Edwards D, Holmes $\mathrm{H}$, Hollingdale A, Evans L, Allen R. Identification of the lateral position of a virtual object based on echoes by humans. Hear Res. 2013;300:e56-65.

8. Schornich S, Nagy A, Wiegrebe L. Discovering your inner bat: echo-acoustic target ranging in humans. J Assoc Res Otolaryngol. 2012;13:e67382.

9. Schenkman BN, Nilsson ME. Human echolocation: blind and sighted persons' ability to detect sounds recorded in the presence of a reflecting object. Perception. 2010;39(4):483.

10. Kolarik AJ, Cirstea S, Pardhan S, Moore BCJ. A summary of research investigating echolocation abilities of blind and sighted humans. Hear Res. 2014;310:60-8.

11. Conroy RM. Sample sizes and powers for comparing two means where the variable is measured on a continuous scale that is (more or less) normally distributed. The RCSI Sample size handbook 2016. p. 27-33.

12. World Health Organization. Prevention of blindness and deafness estimates. Geneva, Switzerland: World Health Organization; 2012 [January 8, 2015]; Available from: http://www.who.int/pbd/deafness/estimates/en/.

13. Collignon O, Davare M, Olivier E, De Volder AG. Reorganisation of the Right Occipito-Parietal Stream for Auditory Spatial Processing in Early Blind Humans. A Transcranial Magnetic Stimulation Study. Brain Topogr. 2009;21(34):232-40

14. Thaler L, Arnott SR, Goodale MA. Neural correlates of natural human echolocation in early and late blind echolocation experts. PloS one. 2011;6:e20162.

15. Voss P, Tabry V, Zatorre RJ. Trade-off in the sound localization abilities of early blind individuals between the horizontal and vertical planes. The Journal of neuroscience : the official journal of the Society for Neuroscience. 2015;35(15):60516. Epub 2015/04/17.

16. Kolarik AJ, Moore BC, Zahorik P, Cirstea S, Pardhan S. Auditory distance perception in humans: a review of cues, development, neuronal bases, and effects of sensory loss. Attention, perception \& psychophysics. 2016;78(2):373-95. Epub 2015/11/22.

17. Brewton D, Gutierrez V, Razak KA. Accurate sound localization behavior in a gleaning bat, Antrozous pallidus. Scientific reports. 2018;8(1):13457. Epub 2018/09/09.

18. Rowan D, Papadopoulos T, Edwards D, Holmes $\mathrm{H}$, Hollingdale A, Evans L, et al. Identification of the lateral position of a virtual object based on echoes by humans. Hearing research. 2013;300:56-65.

19. Rowan D, Papadopoulos T, Edwards D, Allen R. Use of binaural and monaural cues to identify the lateral position of a virtual object using echoes. Hearing research. 2015;323:32-9.

20. Nilsson ME, Schenkman BN. Blind people are more sensitive than sighted people to binaural sound-location cues, particularly inter-aural level differences. Hear Res. 2016;332:223-32. Epub 2015/10/04. 
Table 1: Measures of central tendency regarding Audiometric values for the two groups (blind and normal sighted students)

\begin{tabular}{lllllll}
\hline & $\begin{array}{l}\text { Total } \\
\text { size } \\
(\mathrm{N})\end{array}$ & $\begin{array}{l}\text { Mean } \\
(\mathrm{dB})\end{array}$ & $\begin{array}{l}\text { Median } \\
(\mathrm{dB})\end{array}$ & SD & Range & CI 95\% \\
\hline $\begin{array}{l}\text { Group 1 (blind } \\
\text { student threshold }\end{array}$ & 23 & 17.45 & 18.75 & 1.98 & 6.25 & $(16.59-18.30)$ \\
$\begin{array}{l}\text { scores) } \\
\begin{array}{l}\text { Group 2 (normal } \\
\text { student threshold } \\
\text { scores) }\end{array}\end{array}$ & 23 & 17.59 & 17.50 & 3.91 & 15.00 & $(15.90-19.28)$ \\
\hline
\end{tabular}

Table 2: Output summary table of audiometric values ranking for the 2 groups

\begin{tabular}{lllll}
\hline & Total scores & $\mathrm{N}$ & $\begin{array}{l}\text { Mean } \\
\text { Rank }\end{array}$ & $\begin{array}{l}\text { Sum of } \\
\text { Ranks }\end{array}$ \\
\hline $\begin{array}{l}\text { Audiometric } \\
\text { hearing } \\
\begin{array}{l}\text { threshold } \\
\text { values }\end{array}\end{array}$ & Blind group & 23 & 22.76 & 523.50 \\
& Normal sighted group & 23 & 24.24 & \\
& Total & 46 & & 557.50 \\
\hline
\end{tabular}

Table 3: Showing test statistics and the significance level of the analysis.

\begin{tabular}{ll}
\hline & $\begin{array}{l}\text { Audiometric } \\
\text { hearing } \\
\text { threshold } \\
\text { values }\end{array}$ \\
\hline Mann-Whitney U & 247.500 \\
Wilcoxon W & 523.500 \\
Z & -.380 \\
Asymp. Sig. (2-tailed) & .704 \\
Exact Sig. (2-tailed) & .711 \\
\hline
\end{tabular}

